\title{
Graphite oxide-based graphene materials as positive electrodes in vanadium redox flow batteries
}

\author{
Zoraida González, Cristina Botas, Clara Blanco ", Ricardo Santamaría, Marcos Granda, \\ Patricia Álvarez, Rosa Menéndez \\ Instituto Nacional del Carbón (INCAR-CSIC) Apdo. 73, 33080-Oviedo, Spain
}

\begin{abstract}
Two graphene materials, TRGO-1 and TRGO-2, prepared by the thermal exfoliation/reduction at $1000^{\circ} \mathrm{C}$ of two graphite oxides with different characteristics, are investigated as positive electrodes in a Vanadium Redox Flow Battery (VRFB). A detailed study of their electrochemical response towards the $\left[\mathrm{VO}_{2}^{+}\right] /\left[\mathrm{VO}^{2+}\right]$ redox system is carried out through cyclic voltammetry, electrochemical impedance spectroscopy and charge/discharge experiments. As a consequence of the differences in the structure of the parent graphite oxides, TRGO-1 and TRGO-2 exhibit different structural and physicochemical properties resulting in significantly different electrochemical performances towards the vanadium redox reactions. TRGO-1 exhibits a markedly enhanced electrochemical activity (higher peak current densities and lower overpotentials) and a better kinetic reversibility towards the oxidation/reduction vanadium processes than TRGO-2. Furthermore, charge/discharge tests performed on two VRB single cells, the only differing component being the positive electrode, present higher coulombic, voltage and energy efficiency values in that battery containing the TRGO-1 electrode. The better results achieved with this sample are attributed to the higher degree of restoration of the $2 \mathrm{D}$ graphitic structure, and to the consequently higher electrical conductivity which increases the heterogeneous electron transfer rate. Moreover, residual hydroxyl groups present may act as active reaction sites and contribute to enhance its electrochemical response.
\end{abstract}

\footnotetext{
* Corresponding author: Fax: +34 9852976 62. E-mail address: clara@incar.csic.es (C. Blanco)
} 
Keywords: vanadium redox flow battery, graphene material, 2D graphitic structure, surface chemistry, charge transfer, electrochemical activity.

\section{Introduction}

New sources of renewable energy have been developed in recent years in an attempt to achieve sustainable energy production. Although they offer clean energy, their intermittent nature in terms of power generation/power demand makes it necessary to storage the energy. There is therefore great interest amongst the scientific community to develop electrochemical energy storage systems [1].

Vanadium Redox Flow Batteries (VRFBs) have attracted increasing interest as large-scale energy storage devices because they offer attractive features such as a long life, a flexible design, a high energy efficiency and a low maintenance cost [2]. Unlike other batteries, where the energy is stored in the electrodes, VRFBs store this energy through the redox reactions of the electroactive species contained in two separate solutions [3]. Thus, ensuring the inertness of the electrodes, they offer the possibility of acting separately on the energy capacity and output power, facilitating their scale-up. Moreover, the use of the same metal in both halfcells $\left(\left[\mathrm{VO}_{2}{ }^{+}\right] /\left[\mathrm{VO}^{2+}\right]\right.$ in the positive electrolyte and $\mathrm{V}^{3+} / \mathrm{V}^{2+}$ in the negative one), eliminates the problem of cross-contamination, the main cause of self-discharge in other redox flow batteries [4].

Although the electrodes are not direct storage elements, they have a key role to play in VRFBs by providing sites for the electrochemical reactions necessary for the proper operation of the battery. Consequently, the selection of suitable electrode materials, with a high electrical conductivity, a high surface area, high mechanical strength, a good electrolyte stability and electrochemical activity [5], is of fundamental importance for obtaining a battery with an excellent performance. The poor kinetics and reversibility of commonly used graphite felts [6], carbon cloths [7] and carbon fibers [8] restrict their use as active electrodes. 
This drawback, together with the tedious procedures required to improve their electrochemical performance $[9,10]$, makes it necessary to search for new electrode materials. Graphenes have emerged as promising active electrode materials in electrochemical devices, due to their unique properties i.e., a high electrical conductivity, a high surface-to-volume ratio, mechanical stability and widely applicable electrochemical activity [11]. Furthermore, the possibility to prepare bulk quantities of graphene materials through readily scalable chemical methods, like the graphite oxide route, has increased the interest of scientists in their possible use as electrodes in energy-efficient storage/generation systems such as supercapacitors [12], lithium-ion batteries [13] or fuel cells [14].

The thermal exfoliation/reduction of graphite oxide (GO) has been widely investigated for the preparation of graphene $[15,16]$ due to its simplicity, sustainability and scalability. Moreover, this method offers the possibility of controlling the quality of the materials produced by taking into account the characteristics of parent graphite [17], the oxidation method used in the preparation of the graphite oxide [18] and the conditions employed for the thermal reduction of the graphite oxide to graphene [19]. The resulting materials can thus be tailored to exhibit different structures and functionalities and by implication different electrochemical properties [20].

In a previous paper [21] the authors investigated the suitability of graphene materials, prepared by the direct thermal exfoliation/reduction of a synthetic graphite-based GO at different temperatures, as positive electrodes in a VRFB and observed an excellent behavior in that obtained at $1000{ }^{\circ} \mathrm{C}$. Furthermore, the authors have recently demonstrated the better performance of the materials prepared by the direct thermal exfoliation/reduction of graphite oxide (produced in a single step) compared to those obtained by the thermal reduction of graphene oxide (after exfoliation of the graphite oxide, in a two-step process).

In the present study, we prepared two graphene materials, by the thermal exfoliation/reduction at $1000^{\circ} \mathrm{C}$ of graphite oxides with different characteristics and investigated the influence of 
their different structural and physico-chemical properties on the electrochemical performance of the electrodes. A detailed study of their response towards the $\left[\mathrm{VO}_{2}^{+}\right] /\left[\mathrm{VO}^{2+}\right]$ redox system was carried out through cyclic voltammetry, electrochemical impedance spectroscopy and charge/discarge experiments. As the electrochemical kinetic limitation of VRFBs is in the positive side [22], an understanding of how the different structural and physico-chemical properties of the graphene materials influence their electrochemical performance is key to the development of more active positive electrodes and, consequently, more efficient batteries.

\section{Experimental}

\subsection{Synthesis of graphene materials}

Two graphite oxides, GO-1 and GO-2, were obtained by the oxidative treatment of two synthetic graphites with different characteristics [23] using a modified Hummers method [24]. This method makes use of Hummers reagents combined with additional amounts of $\mathrm{NaNO}_{3}$ and $\mathrm{KMnO}_{4}$. Concentrated $\mathrm{H}_{2} \mathrm{SO}_{4}(360 \mathrm{~mL})$ was added to a mixture of the corresponding synthetic graphite $(7.5 \mathrm{~g})$ and $\mathrm{NaNO}_{3}(7.5 \mathrm{~g})$, and the resulting mixture was cooled down to 0 ${ }^{\circ} \mathrm{C}$ using an ice bath. $\mathrm{KMnO}_{4}(45 \mathrm{~g})$ was added slowly in small doses to keep the reaction temperature below $20{ }^{\circ} \mathrm{C}$. The as-prepared solutions were heated to $35{ }^{\circ} \mathrm{C}$ and stirred for $3 \mathrm{~h}$. At this point $3 \%$ of $\mathrm{H}_{2} \mathrm{O}_{2}(1.5 \mathrm{~L})$ was slowly added, resulting in a pronounced exothermal effect up to $98^{\circ} \mathrm{C}$. The reaction mixtures were stirred for $30 \mathrm{~min}$ and then centrifuged (3700 rpm for $30 \mathrm{~min}$ ), the supernatants being decanted away. The remaining solid materials were washed with $600 \mathrm{~mL}$ of water and centrifuged again, this process being repeated until the $\mathrm{pH}$ was neutral. Both GO-1 and GO-2 were then thermally treated in a tubular furnace up to 1000 ${ }^{\circ} \mathrm{C}\left(5^{\circ} \mathrm{C} \mathrm{min}{ }^{-1}\right)$ for $1 \mathrm{~h}$, under a $\mathrm{N}_{2}$ flow of $100 \mathrm{~mL} \mathrm{~min}^{-1}$ to obtain the two graphene materials (TRGO-1 and TRGO-2, respectively). 


\subsection{Structural, chemical and physical characterization}

The morphology of the samples was studied by SEM (using a FEI model Quanta FEG 650 instrument operating at $5 \mathrm{KV}$ ) and TEM (on a JEOL 2000 EX-II). Raman spectra were recorded, from 750 to $3500 \mathrm{~cm}^{-1}$, on a Renishaw 2000 Confocal Raman Microprobe (Rhenishaw Instruments, England) using a 514.5-nm argon ion laser. The apparent BET surface areas were determined by applying the BET equation to the nitrogen adsorption isotherms obtained at $77 \mathrm{~K}$ on a Micromeritics ASAP $^{\circledR} 2420$ instrument. The electrical conductivity of the samples was measured (at $20 \mathrm{MPa}$ ) using a modification of the four-probe method of Van der Pauw [25]. The atomic oxygen content on the surface was determined by XPS analysis in a VG-Microtech Multilab 3000 spectrometer (SPECS, Germany) equipped with a hemispherical electron analyser and a $\operatorname{MgK} \alpha(h v=1253.6 \mathrm{eV}) \mathrm{X}$-ray source. The type of bonding and the functional groups present in the samples were estimated from the XPS C1s spectra. Therefore, curve fitting of the $\mathrm{C} 1 \mathrm{~s}$ spectra was performed using a GaussianLorentzian peak shape after performing a Shirley background correction [26]. The resulting spectra show the binding energy of the $\mathrm{C}=\mathrm{C}\left(\mathrm{sp}^{2}\right)$ at $284.5 \mathrm{eV}$. The chemical shifts of +1.0 and $+2.1 \mathrm{eV}$ were assigned to the $\mathrm{C}\left(\mathrm{sp}^{3}\right)$ hybridisation and $\mathrm{C}-\mathrm{OH}$ functional groups, respectively [27].

\subsection{Electrochemical measurements}

Cyclic voltammetry (CV) and electrochemical impedance spectroscopy (EIS) experiments were performed in a Swagelok ${ }^{\circledR}$ type three-electrode cell at room temperature. The cell consisted of samples of TRGO-1 or TRGO-2, as the working electrode, $\mathrm{Hg} / \mathrm{Hg}_{2} \mathrm{SO}_{4}$ as the reference electrode and a platinum gauze acting as the counter electrode. Both working electrodes were disk-shaped with the same geometric area $\left(0.5 \mathrm{~cm}^{2}\right)$ and the same mass $(25$ $\mathrm{mg}$ ), consisting of $70 \mathrm{wt} \%$ of active material and $30 \mathrm{wt} \%$ of polyvinylidene fluoride (as binder). The electrodes were dried in a vacuum oven at $110^{\circ} \mathrm{C}$ overnight before each 
experiment. All the potentials in this study are quoted with reference to $\mathrm{Hg} / \mathrm{Hg}_{2} \mathrm{SO}_{4}$ (i.e., 0.65 V vs. NHE). The positive electrolyte consisted of a solution of $0.5 \mathrm{M} \mathrm{VOSO}_{4}$ (Sigma Aldrich) in $1.0 \mathrm{M} \mathrm{H}_{2} \mathrm{SO}_{4}$ (VWR International). Electrochemical measurements were performed on a Biologic VMP Multichannel Potentiostat.

In the $\mathrm{CV}$ experiments the potential sweeps always started from the open circuit potential (OCP), the initial scan direction being positive. The scan rate, $v_{\text {scan }}$, was varied from 1 to50 $\mathrm{mVs}^{-1}$. Repetitive voltammograms $\left(25\right.$ scans) were recorded at each $v_{\text {scan }}$ to evaluate the long term stability of the electrode materials and to study the kinetics of the vanadium redox processes.

EIS measurements were performed at a polarization potential of $0.4 \mathrm{~V}\left(\mathrm{vs} \mathrm{Hg} / \mathrm{Hg}_{2} \mathrm{SO}_{4}\right)$ and amplitude of $10 \mathrm{mV}$ over a frequency range of $100 \mathrm{KHz}$ to $500 \mathrm{mHz}$.

\subsection{Single cell test}

Two lab-scale static vanadium redox batteries (VRBs) were assembled, the only differing component being the positive electrode. Disk-shaped electrodes of TRGO-1 (in VRB-1) or TRGO-2 (in VRB-2) were placed in the positive half-cell. Likewise, in both cases, pieces of thermally treated graphite felt (TTGF), a standard electrode material in these types of batteries, acted as the negative electrodes. For the charge/discharge experiments, the active area of each electrode was $1 \mathrm{~cm}^{2}$. The two compartments of each cell were separated by a commercial membrane $\left(\right.$ Nafion ${ }^{\circledR}$ NRE-212) and gold disks were used as current collectors. The starting electrolytes for the positive and negative half-cells were solutions of $0.5 \mathrm{M}$ $\mathrm{VOSO}_{4} / 1.0 \mathrm{M} \mathrm{H}_{2} \mathrm{SO}_{4}$ and $0.5 \mathrm{M} \mathrm{VCl}_{3}$ (Aldrich) / $1.0 \mathrm{M} \mathrm{H}_{2} \mathrm{SO}_{4}$ (each electrolyte volume being approximately $1 \mathrm{~mL}$ ), respectively. Charge/discharge experiments were carried out in both VRBs, applying constant current densities of 10-50 $\mathrm{mAcm}^{-2}$. The upper and lower limit of the charge/discharge voltages was fixed at $1.5 \mathrm{~V}$ and $1.2 \mathrm{~V}$, respectively. 


\section{Results and discussion}

\subsection{Characterization of graphene materials}

The graphite oxides used as raw materials for the synthesis of the graphene materials had similar oxygen contents $(\mathrm{C} / \mathrm{O}$ ratios of about 2$)$ but different types and distributions of oxygen functional groups. GO-1 exhibited a larger proportion of epoxi groups (mainly located at the basal planes) while GO-2 contained predominantly hydroxyl and carboxyl groups (located at the edges of the sheets) [23]. After thermal reduction, the obtained samples, TRGO-1 and TRGO-2, showed a typical fluffy appearance [28], consisting of graphene-like sheets with a disordered stacking as can be seen from the SEM images (Figures 1(a) and a(b)), and displayed similar BET surface areas (Table 1). Moreover, as observed by TEM (Figure 1(c) and (d)), the graphene sheets are corrugated in both samples, although TRGO-2 exhibits more wrinkles and folds.

The high $\mathrm{I}_{\mathrm{D}} / \mathrm{I}_{\mathrm{G}}$ ratios measured by Raman spectroscopy (Table 1) indicate that both materials present quite a high density of defects and, therefore, the average size of the restored $\mathrm{sp}^{2}$ domains in the graphene sheets is relatively small [29]. However, the higher $I_{D} / I_{G}$ value in TRGO-2 may cause their electrochemical behaviors to differ [20].

Additionally, differences in their chemical composition were observed. The XPS analyses of the two graphene samples show that the effectiveness of the thermal treatment in removing the oxygen functional groups [30] is better in TRGO-1 than in TRGO-2, as shown by the C/O ratio measured (Table 1). Moreover, an analysis of the $\mathrm{C} 1 \mathrm{~s}$ spectra, to calculate the functional groups of the samples, confirms the better recovery of the 2D graphitic structure in TRGO-1 as evidenced by its higher $\mathrm{C}$-sp $\mathrm{sp}^{2}$ content $(78.3 \%$ vs $73.2 \%$ for TRGO-2). This explains its higher electrical conductivity (Table 1) [31] which contributes to a better electrochemical performance when used as active electrode material . 
Furthermore, both samples contain residual oxygen functional groups with binding energies in the region corresponding to $\mathrm{C}-\mathrm{OH}$ (Table 1). According to previous studies such hydroxyl groups could act as active sites towards the vanadium redox reactions [32].

\subsection{Electrochemical performance}

The electrochemical behavior of the two graphene samples as electrode materials in the positive half-cell of a VRFB was investigated by means of CV experiments (Figure 2). Taking into account the differences in the structural and physico-chemical properties of the materials, different electrochemical performances towards the vanadium redox reactions might be expected.

As can be seen from Figure 2, the two graphene materials respond positively to the vanadium redox processes under study. This is evidenced by the development, in both voltammograms, of the anodic/cathodic peaks associated to the corresponding $\mathrm{VO}^{2+}$ oxidation and $\mathrm{VO}_{2}^{+}$ reduction reactions. However, there are significant differences in their electrochemical performance, as indicated by the shape of the curves and the electrochemical data obtained from them (Table 2).

The peak current densities $\left(j_{p a}, j_{p c}\right)$ measured on TRGO-2 are smaller than on TRGO-1, contrary to what might be expected considering the slightly higher BET surface area and greater amount of oxygen functional groups in TRGO-2 [33]. Furthermore, the peaks developed on the corresponding $\mathrm{CV}$ are asymmetrical. All these factors confirm the poorer electrochemical activity of TRGO-2 [34], probably due to its greater number of structural defects and lower electrical conductivity (Table 1).

TRGO-1 displays a better electrochemical performance, since it exhibits not only higher $j_{p a}$, $j_{p c}$ and lower peak potential values $\left(E_{p a}, E_{p c}\right)$, but also a lower peak potential separation value $\left(\Delta E_{p}\right)$. These good results are not only indicative of a better electrochemical activity, but also suggest an enhancement of the reversibility of the redox processes on this electrode. 
Furthermore, the $\Delta E_{p}$ measured on this electrode when the scan rate is increased to $20 \mathrm{mVs}^{-1}$ (Figure 2(b)) is much lower than that corresponding to TRGO-2 (where neither the anodic nor the cathodic peaks are well-developed) indicating a lower polarization in the TRGO-1 electrode [35]. Its improved electrochemical performance could be attributed mainly to the less defective structure of the restored graphitic lattice (higher $\mathrm{C}-\mathrm{sp}^{2}$ bond fraction). This would lead to a higher electrical conductivity in this graphene sample and an increased heterogeneous electron transfer rate [36]. The above mentioned residual $\mathrm{C}-\mathrm{OH}$ groups also contribute to this enhanced electrochemical performance by acting as active sites towards the vanadium redox processes [32]. These encouraging results are not only better than those previously reported for other graphene-related materials by other authors [37], but are also comparable to the best results obtained with metal-modified graphite felt [38].

CVs at increasing scan rates (from 1 to $50 \mathrm{mVs}^{-1}$ ) were recorded to investigate the kinetics of the vanadium redox processes on the TRGO-1 electrode (Figure 2(c)). A linear relationship between the anodic and cathodic peak currents and the square root of the scan rate was found (Figure S1, Supporting Information). This result demonstrates that the oxidation of $\mathrm{VO}^{2+}$ and the reduction of $\mathrm{VO}_{2}{ }^{+}$are mainly controlled by their diffusion from the electrolyte to the electrode surface. This agrees with the faster electron transfer rate observed on TRGO-1 [39]. In addition, repetitive CVs were recorded on this electrode (Figure 2(d)) without any significant change in the values of the main electrochemical parameters (peak current densities or potential values). This can be considered as the first tentative evidence of the long-term stability of this active electrode material, even after 125 cycles of potential variation.

In order to investigate in depth the resistance of the graphene materials to the above mentioned electron transfer step, electrochemical impedance spectroscopy (EIS) measurements were carried out. Figure 3 displays the Nyquist plots obtained on both the 
TRGO-1 and TRGO-2 electrodes, in a $\left[\mathrm{VO}_{2}{ }^{+}\right] /\left[\mathrm{VO}^{2+}\right]$ solution at $0.4 \mathrm{~V}$ (according to the CV results shown in Figure 2).

The radius of the semicircle developed in the high frequency range is related to the charge transfer resistance $\left(R_{C T}\right)$ involved in the $\mathrm{VO}^{2+}$ oxidation at the electrode/electrolyte interface [38]. This radius value is smaller for the TRGO-1 electrode, implying a faster electron transfer reaction and corroborating the CV results discussed previously. Additionally, the Z' value at $\mathrm{Z}^{\prime \prime}=0 \Omega$, including the ohmic resistance of the electrolyte, the working electrode and the contact resistance is also smaller for TRGO-1 ( $3 \Omega$ vs $\sim 4 \Omega$ for TRGO-2 electrode). These results are mainly ascribed to the higher electrical conductivity of TRGO-1 (higher content in $\mathrm{sp}^{2}$-hibrydized $\mathrm{C}$ atoms) and confirm its better electrochemical performance as positive electrode in the VRFB.

\subsection{Performance of the VRB single cell}

Charge/discharge experiments, at constant current densities ranging from 10 to $50 \mathrm{mAcm}^{-2}$, were carried out in the two assembled batteries. It is important to remark that the only component that distinguishes them is the positive electrode, the rest of the cell design being the same in both cases. Therefore, any changes in average coulombic $\left(\eta_{C}\right)$, voltage $\left(\eta_{V}\right)$ and energy $\left(\eta_{E}\right)$ efficiency, calculated from these tests (Table 3), can only be ascribed to changes in the positive electrode [40].

The efficiencies of VRB-1 at all the current densities tested are higher than those of VRB-2. As a consequence of the better reversibility of the $\left[\mathrm{VO}_{2}^{+}\right] /\left[\mathrm{VO}^{2+}\right]$ redox processes on the TRGO-1 electrode and the lower electrochemical polarization of this electrode (see CVs, Figure 2), the coulombic efficiency of VRB-1 is clearly improved [41]. Moreover, the lower polarization of the electrode during the charge/discharge steps could explain the slightly higher voltage efficiency obtained with this static battery [42]. 
In addition, the evolution of the charge/discharge performances of both VRBs when cycling, at $50 \mathrm{mAcm}^{-2}$, is presented in Figure 4. It can be seen that the efficiencies of both VRBs remain stable with cycling (Figure 4(a)) although the values obtained for VRB-1 are consistently higher than those corresponding to VRB-2 and are comparable to previously reported values $[32,41]$. This confirms the better performance of VRB-1, which is ascribed to the reported better electrochemical performance of TRGO-1 towards the $\left[\mathrm{VO}_{2}^{+}\right] /\left[\mathrm{VO}^{2+}\right]$ redox reactions

\section{Conclusions}

The graphene materials TRGO-1 and TRGO-2, obtained by the thermal exfoliation/reduction at $1000^{\circ} \mathrm{C}$ of graphite oxides with distinct characteristics, present different structural and physicochemical properties which result in different electrochemical performances towards the $\mathrm{VO}^{2+} / \mathrm{VO}_{2}{ }^{+}$redox reactions. TRGO-1 is shown to be the more suitable positive electrode in the VRFB, as it exhibits a markedly enhanced electrochemical activity (higher peak current densities and lower redox reactions overpotentials) and a better kinetic reversibility towards these oxidation/reduction vanadium processes than TRGO-2. Furthermore, when the TRGO-1 electrode is tested by means of charge/discharge experiments in the positive side of a single cell, better coulombic, voltage and energy efficiency values are obtained. These encouraging results are mainly attributed to the better restoration of the $2 \mathrm{D}$ graphitic structure in this sample (as reflected by the higher $\mathrm{C}-\mathrm{sp}^{2}$ content). Consequently, a higher electrical conductivity is achieved which increases the heterogeneous electron transfer rate. In addition, the residual $\mathrm{C}-\mathrm{OH}$ groups present in TRGO-1 may act as active reaction sites and contribute to enhance the electrochemical response. 


\section{Acknowledgements}

The authors thank MICINN (CONSOLIDER INGENIO 2010, Ref. CSD2009-00050 and

Subprograma INNPACTO, Ref. IPT-2011-1690-920000), FICYT (Programa Operativo FEDER 2007-2013, Project PC10-35) and HC Energía for their financial support. Dr. Patricia Alvarez thanks MICINN for her Ramon y Cajal research contract.

\section{References}

1. L. Joerissen, J. Garche, Ch. Fabjan, G. Tomazic, J. Power Sources 127 (2004) 98-104.

2. C. Ponce de León, A. Frías-Ferrer, J. González-García, D.A. Szánto, F.C. Walsh, J. Power Sources 160 (2006) 716-732.

3. M. Skyllas-Kazacos, M. Rychick, R. Robins, US Patent, 4786567, 1988.

4. M. Bartolozzi, J. Power Sources 27 (1989) 219-226.

5. V. Haddadi-Asl, M. Kazacos, M. Skyllas-Kazacos, J. Appl. Electrochem. Sci. 25 (1995) 29-33

6. S. Zhong, C. Paeste, M. Skyllas-Kazacos, J. Power Sources 45(1) (1993) 29-41.

7. H. Kaneko, K. Nozaki, Y. Wada, T. Aoki, A. Negishi, M. Kamimoto, Electrochim. Acta 36(7) (1991)1191-1196.

8. S.K. Kamarudin, W.R.W. Daud, S.L. Ho, U.A. Hasran, J. Power Sources 163(2) (2007) 743-754.

9. B. Sun, M. Skyllas-Kazacos, Electrochim. Acta 37 (1992) 1253-1260.

10. B. Sun, M. Skyllas-Kazacos, Electrochim. Acta 37 (1992) 2459-2465.

11. D. Chen, L. Tang, J. Li, Chem. Soc. Rev. 39 (2010) 3157-3180.

12. Y. Wang, Z. Shi, Y. Huang, Y. Ma, C. Wang, M. Chen, Y. Chen, J. Phys. Chem. C 113 (2009) 13103-13107. 
13. E.J. Yoo, J. Kim, E. Hosono, H.S. Zhou, T. Kudo, I. Honma, Nano Lett. 8 (2008) $2277-2282$.

14. L. Qu, Y.J. Baek, L. Dai, ACS Nano 4 (2010) 1321-1326.

15. J. Xia, F. Chen, J. Li, N. Tao, Nat. Nanotechnol. 4 (2009) 505-509.

16. M.J. McAllister, J.L. Li, D.H. Adamson, H.C. Schniepp, A.A. Abdala, J. Liu, M.H. Alonso, D.L. Milius, R. Car, R.K. Prud'homme, I.A. Aksay, Chem. Mater. 19 (2007) 4396-4404.

17. Z.S. Wu, W. Ren, L. Gao, B. Liu, C. Jiang, H.M. Cheng, Carbon 47 (2009) 493-499.

18. D.C. Marcano, D.V. Kosynkin, J.M. Berlin, A. Sinitskii, Z. Sun, A. Slesarev, L.B. Alemany, W. Lu, J.M. Tour, ACS Nano 4 (2010) 4806-4814.

19. D. Zhan, Z. Ni, W. Chen, L. Sun, Z. Luo, L. Lai, T. Yu, A.T.S. Wee, Z. Shen Carbon 49 (2011) 1362-1366.

20. A. Ambrosi, A. Bonanni, Z. Soler, J.S. Cross, M. Pumera, Chem, Eur. J. 17 (2011) 10763-10770.

21. Z. González, C. Botas, P. Álvarez, S. Roldán, C. Blanco, R. Santamaría, M. Granda, R. Menéndez, Carbon 50 (2012) 828-834.

22. Y. Shao, X. Wang, M. Engelhard, C. Wang, S. Dai, J. Liu, Z. Yangm Y. Lin, J. Power Sources 195 (2010) 4375-4379.

23. C. Botas, P. Álvarez, C. Blanco, R. Santamaría, M. Granda, P. Ares, F. RodríguezReinoso, R, Menéndez, Carbon 50 (2012) 275-282.

24. W.S. Hummers, R.E. Offeman, J. Am. Chem. Soc. 80 (1958) 1339- 1340.

25. L.J. Van der Pauw, Philips Tec. Rev. 20 (1958) 220-224.

26. P.M.A. Sherwood, D. Briggs, M.P. Seah, Practical Surface Analysis, vol. 1, Auger and X-ray Photoelectron Spectroscopy, Wiley, New York, 1990.

27. D. Deng, X. Pan, L. Yu, Y. Cui, Y. Jiang, J. Qi, W.-X. Li, Q. Fu, X. Ma, Q. Xue, G. Sun, X. Bao, Chem. Mater., 23 (2011) 1188-1193. 
28. C. Botas, P. Álvarez, C. Blanco, R. Santamaría, M. Granda, M.D. Gutiérrez, F. Rodríguez-Reinoso, R. Menéndez, Carbon 52 (2012) 476-485.

29. S. Kurita, A. Yoshimura, H. Kawamoto, T. Uchida, K. Kojima, M. Tachibana, P. Molina-Morales, H. Nakai, J. Appl. Phys. 97 (2005) 104320-104325.

30. D. Yang, A. Velamakanni, G. Bozoklu, S. Park, M. Stoller, R.D. Piner, S. Stankovich, I. Jung, D.A. Field, C.A. Ventrice Jr., R.S. Rufo, Carbon 47 (2009) 145-152.

31. S. Stankovich , D.A. Dikin , G.H. Dommett , K.M. Kohlhaas , E.J. Zimney , E.A. Stach , R.D. Piner, S.T. Nguyen, R.S. Ruoff . Nature 442 (2006) 282-286.

32. C. Gao, N.F. Wang, S. Peng, S.Q. Liu, Y. Lei, X.X. Liang, S. Zeng, H. Zi, Electrochim. Acta 88 (2013) 193-202.

33. W. Li, J. Liu, C. Yan, Carbon 49 (2011) 3463-3470.

34. C. Yao, H. Zhang, T. Liu, X. Li, Z. Liu, J. Power Sources 218 (2012) 455-461.

35. Z. González, A. Sánchez, C. Blanco, M. Granda, R. Menéndez, R. Santamaría, Electrochem. Commun. 13 (2011)1379-1382.

36. J.G.S. Moo, A. Ambosi, A. Bonanni, M. Pumera, Chem. Asian J. 7 (2012) 759-770.

37. P. Han, H. Wang, Z. Liu, X. Chen, W. Ma, J. Yao, Y. Zhu, G. Cui, Carbon 49 (2011) $693-700$.

38. W.H. Wang, X.D. Wang, Electrochim. Acta 52 (2007) 6755-6762.

39. J.H. Kim, K.J. Kim, M.S. Park, N.J. Lee, U. Hwang, H. Kim, Y. Kim, Electrochem. Commun. 13 (2011) 997-1000.

40. K.J. Kim, Y.J. Kim, J.H. Kim, M.S. Park, Mat. Chem. and Phys. 131 (2011) 547-553.

41. G. Wei, C. Jia, J. Liu, C. Yan, J. Power Sources 220 (2012) 185-192.

42. W. Li, J. Liu, C. Yan, Electrochim. Acta 79 (2012) 102-108. 
Table 1. Characteristics of the graphene materials synthesized.

\begin{tabular}{cccccccc}
\multirow{2}{*}{ SAMPLE } & BET & RAMAN & \multicolumn{2}{c}{ XPS } & Conductivity \\
\cline { 2 - 8 } & $\mathrm{S}\left(\mathrm{m}^{2} \mathrm{~g}^{-1}\right)$ & $\mathrm{I}_{\mathrm{D}} / \mathrm{I}_{\mathrm{G}}$ & $\mathrm{C} / \mathrm{O}$ & $\mathrm{Csp}^{2}(\%)$ & $\mathrm{Csp}^{3}(\%)$ & $\mathrm{COH}(\%)$ & $\mathrm{K}\left(\mathrm{Scm}^{-1}\right)$ \\
\hline TRGO-1 & 185 & 1.18 & 15.20 & 78.3 & 17.2 & 4.5 & 0.63 \\
\hline TRGO-2 & 215 & 1.31 & 9.70 & 73.2 & 20.8 & 6.0 & 0.56
\end{tabular}

Table 2. Electrochemical data derived from the CVs recorded on TRGO-1 and TRGO-2 electrodes.

\begin{tabular}{|c|c|c|c|c|c|}
\hline SAMPLE & $\mathbf{v}_{\text {scan }}\left(m V s^{-1}\right)$ & $\mathbf{j}_{\mathrm{pa}}\left(\mathrm{mAcm}{ }^{-2}\right)$ & $\mathrm{j}_{\mathrm{pc}}\left(\mathrm{mAcm}{ }^{-2}\right)$ & $\Delta \mathbf{E}_{p}(\mathbf{V})$ & $\mathbf{I}_{\mathrm{pa}} / \mathbf{I}_{\mathrm{pc}}$ \\
\hline \multirow{5}{*}{ TRGO-1 } & 1 & 24.37 & 21.17 & 0.101 & 1.15 \\
\hline & 5 & 64.01 & 59.02 & 0.214 & 1.08 \\
\hline & 10 & 96.22 & 89.10 & 0.305 & 1.08 \\
\hline & 20 & 142.54 & 135.59 & 0.406 & 1.05 \\
\hline & 50 & 208.74 & 212.72 & 0.610 & 0.98 \\
\hline \multirow{3}{*}{ TRGO-2 } & 1 & 19.28 & 16.32 & 0.285 & 1.18 \\
\hline & 5 & 52.48 & 50.01 & 0.411 & 1.05 \\
\hline & 10 & 74.95 & 70.77 & 0.557 & 1.06 \\
\hline
\end{tabular}


Table 3. Efficiencies of the VRBs with graphene materials as positive electrodes.

\begin{tabular}{|c|c|c|c|c|}
\hline CELL TEST & $\mathrm{j}\left(\mathrm{mAcm}{ }^{-2}\right)$ & $\eta_{C}(\%)$ & $\eta_{E}(\%)$ & $\eta_{V}(\%)$ \\
\hline \multirow{5}{*}{ VRB-1 } & 10 & 50.00 & 47.80 & 95.60 \\
\hline & 20 & 75.00 & 71.95 & 95.93 \\
\hline & 30 & 83.33 & 77.97 & 93.56 \\
\hline & 40 & 87.23 & 80.51 & 92.44 \\
\hline & 50 & 90.48 & 81.61 & 91.58 \\
\hline \multirow{5}{*}{ VRB-2 } & 10 & 46.50 & 44.24 & 95.14 \\
\hline & 20 & 72.50 & 68.86 & 94.98 \\
\hline & 30 & 81.36 & 76.07 & 93.51 \\
\hline & 40 & 85.42 & 78.96 & 92.30 \\
\hline & 50 & 87.80 & 80.41 & 91.20 \\
\hline
\end{tabular}




\section{Figure Captions}

Figure 1. SEM images of: (a) TRGO-1 and (b) TRGO-2. TEM images of: (c) TRGO-1 and (d) TRGO-2.

Figure 2. CVs recorded in a $\mathrm{VOSO}_{4} 0.5 \mathrm{M} / \mathrm{H}_{2} \mathrm{SO}_{4} 1.0 \mathrm{M}$ solution: (a) on TRGOs at $1 \mathrm{mVs}^{-1}$ (b) on TRGOs at $20 \mathrm{mVs}^{-1}$ (c) on TRGO-1 at increasing scan rates, $v_{\text {scan }}$ (d) Repetitive CVs recorded on TRGO-1.

Figure 3. Nyquist plots of the TRGO-1 and TRGO-2 electrodes in a $\mathrm{VOSO}_{4} 0.5 \mathrm{M} / \mathrm{H}_{2} \mathrm{SO}_{4}$ 1.0 M solution at $0.4 \mathrm{~V}$ ( vs $\left.\mathrm{Hg} / \mathrm{Hg}_{2} \mathrm{SO}_{4}\right)$.

Figure 4. Performances of the static VRBs when cycling at $50 \mathrm{mAcm}^{-2}$. 

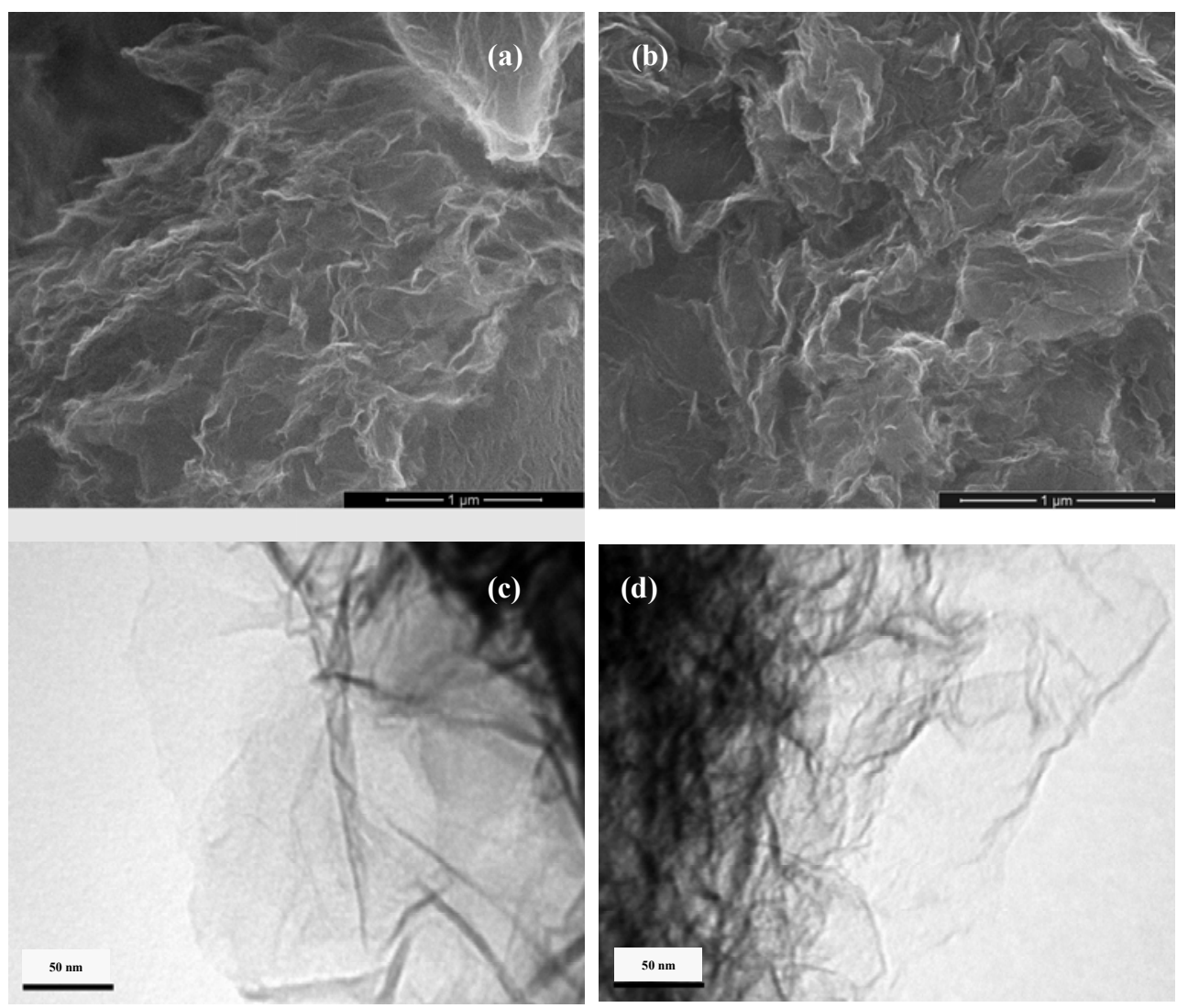

Figure 1 

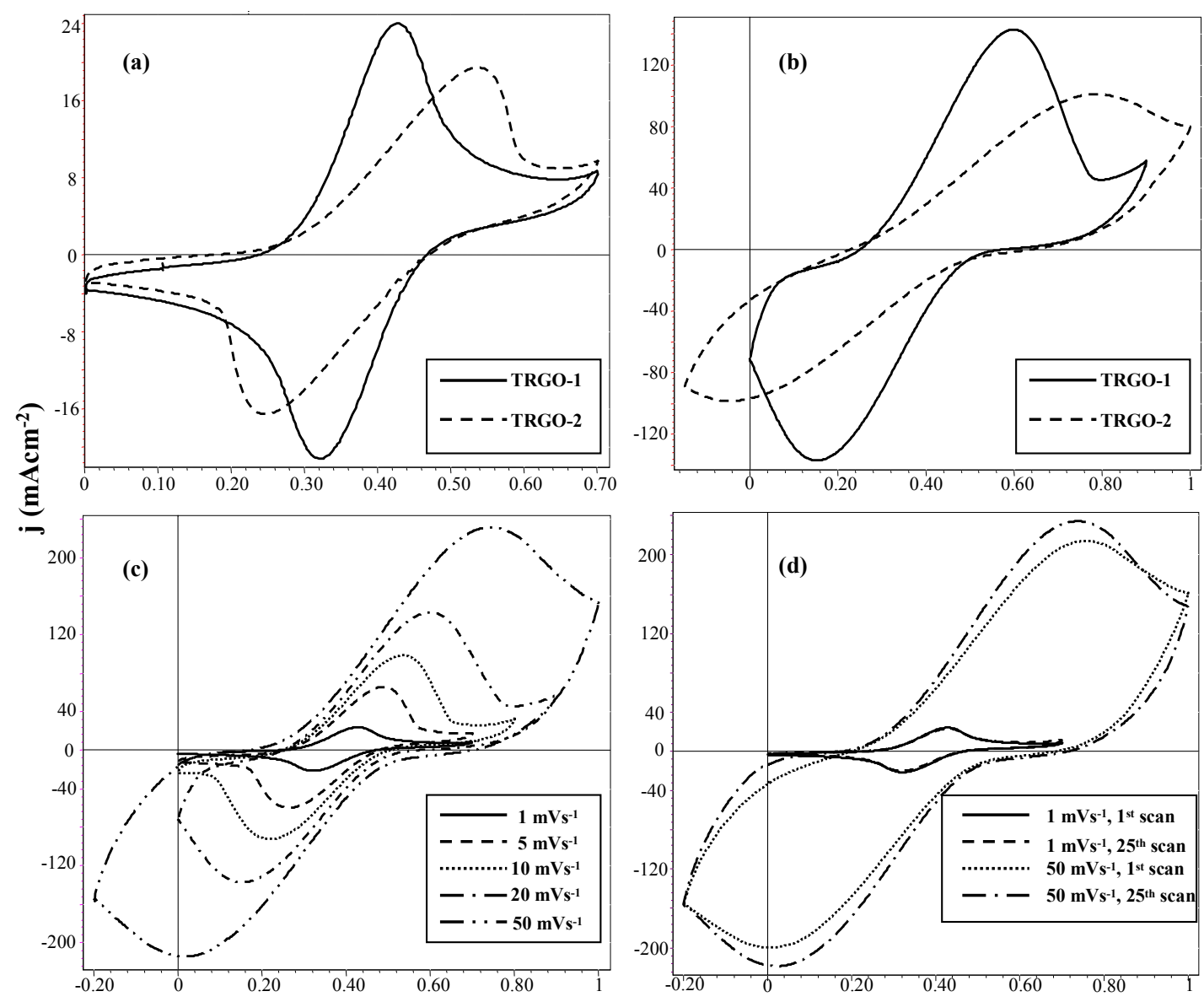

\section{E (V) vs $\mathrm{Hg} / \mathrm{Hg}_{2} \mathrm{SO}_{4}$}

Figure 2 


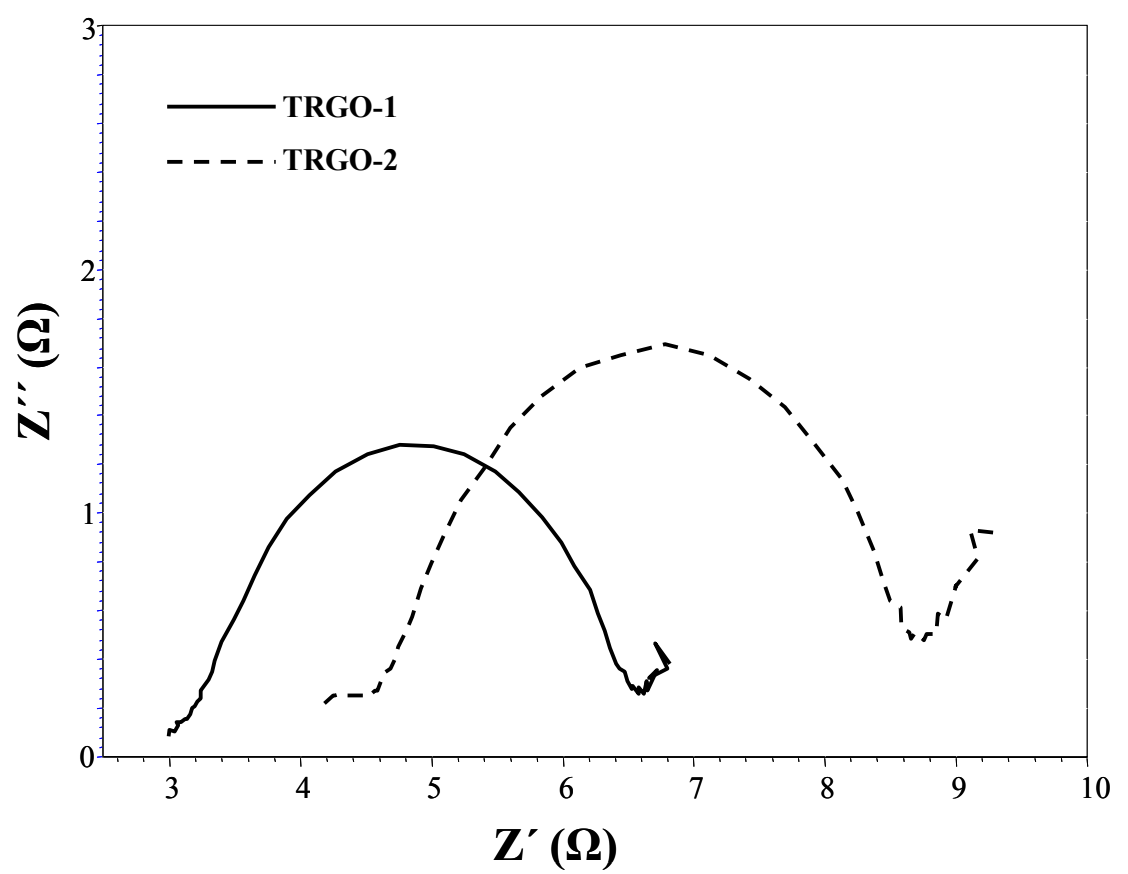

Figure 3

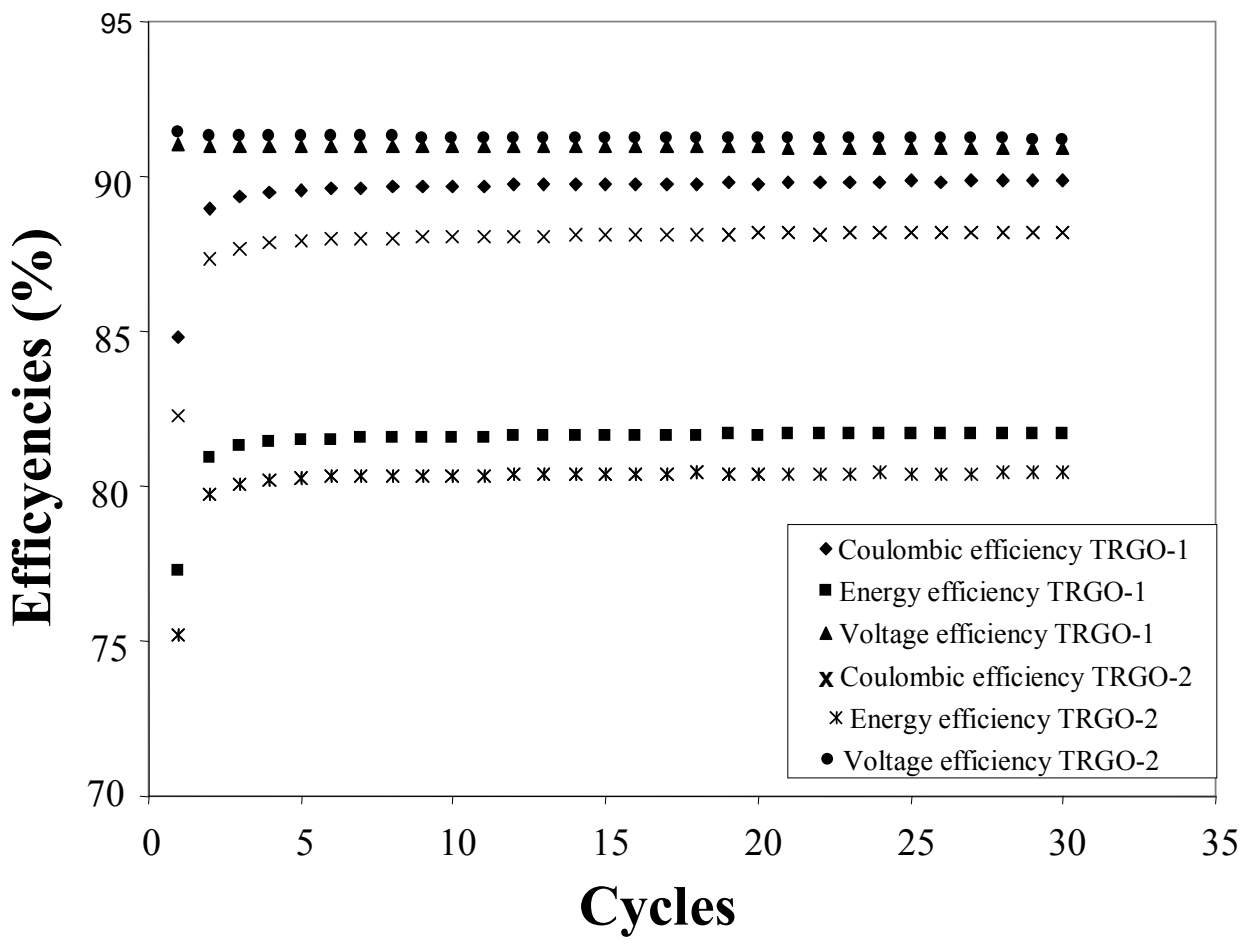

Figure 4 


\section{Supporting Information}

Title Electrochemical performance as positive electrodes in vanadium redox flow batteries of graphene materials obtained from the thermal reduction of graphite oxides with different characteristics

Zoraida González, Cristina Botas, Clara Blanco*, Ricardo Santamaría, Marcos Granda, Patricia Álvarez, Rosa Menéndez

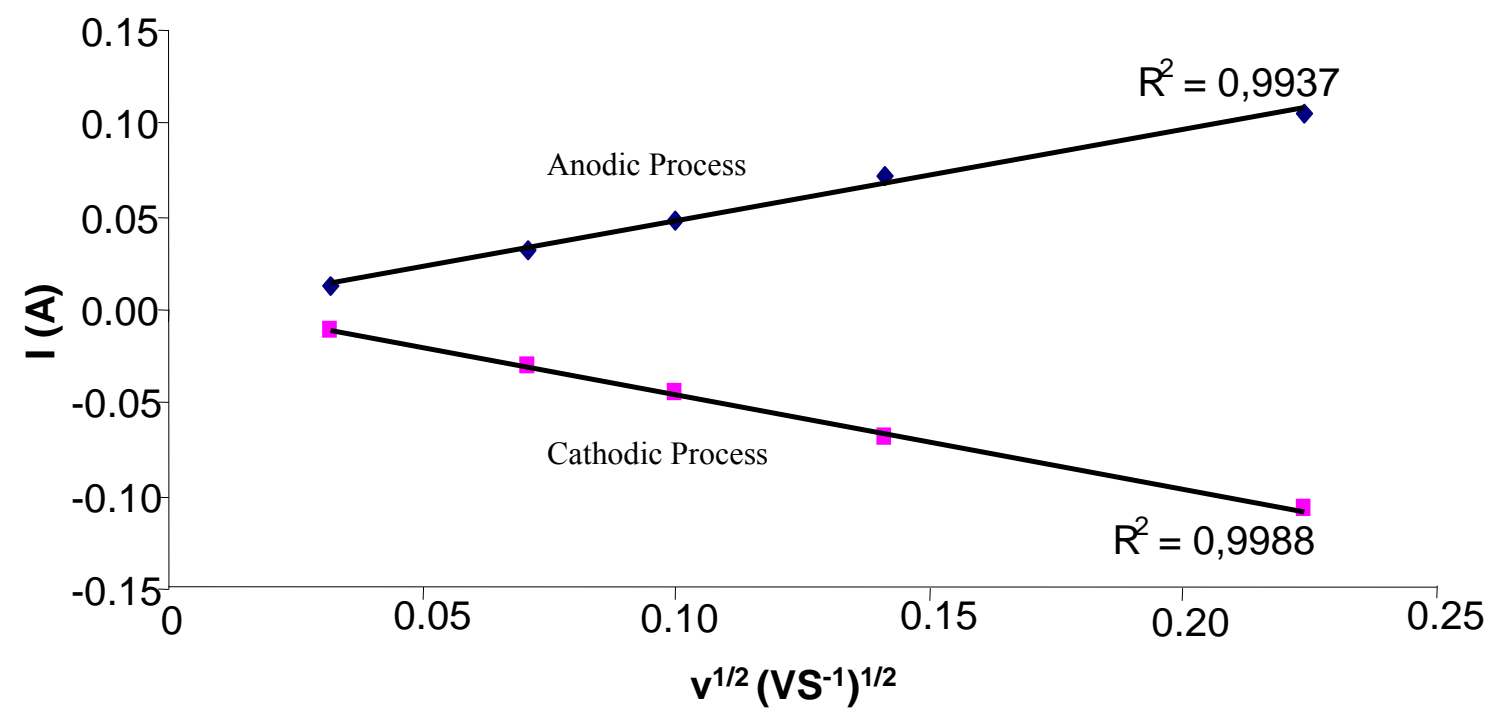

Figure S1. Anodic and cathodic currents measured on the TRGO-1 electrode $v s$ the square root of $v_{\text {scan }}$ 